\title{
Clinical Sign: Clubbing
}

\author{
Maddury Jyotsna ${ }^{1}$ Jagan Mohan Tharakan² \\ ${ }^{1}$ Department of Cardiology, Nizam's Institute of Medical Sciences \\ (NIMS), Punjagutta, Hyderabad, Telangana, India \\ 2 Department of Cardiology, Sree Chitra Tirunal Institute for Medical \\ Sciences and Medical College, Thiruvananthapuram, Kerala, India \\ Indian J Cardiovasc Dis Women-WINCARS 2017;2:e1-e9.
}

Address for correspondence Prof. Maddury Jyotsna, MD, DM, FACC, FESC, FICC, Department of Cardiology, Nizam's Institute of Medical Sciences (NIMS), Punjagutta, Hyderabad 500082, Telangana, India (e-mail: mail2jyotsna@rediffmail.com).

\section{Background}

Since Hippocrates first described digital clubbing in patients with empyema, digital clubbing has been associated with various underlying pulmonary, cardiovascular, neoplastic, infectious, hepatobiliary, mediastinal, endocrine, and gastrointestinal diseases. Finger clubbing also may occur, without evident underlying disease, as an idiopathic form or as a mendelian dominant trait.

\section{Definition}

"Clubbing" is a clinically descriptive term, referring to the bulbous uniform swelling of the soft tissue of the terminal phalanx of a digit with subsequent loss of the normal angle between the nail and the nail bed.

\section{Classification}

Digital clubbing is classified into primary (i.e., idiopathic, hereditary) and secondary forms. Digital clubbing may be symmetric bilaterally, or it may be unilateral or involve a single digit.

\section{Primary Clubbing}

Primary hypertrophic osteoarthropathy (PHO), a rare hereditary disorder with digital clubbing, subperiosteal new bone formation, and arthropathy, has been linked mutations in the 15-hydroxy-prostaglandin dehydrogenase (15-PGDH) encoding gene HPGD, which causes PHO. A mutation was identified in a large Pakistani family with isolated congenital nail clubbing. In another study of homozygous mutations, an intragenic deletion that results in frameshift and a missense mutation was associated with a severe PHO phenotype. A heterozygous carrier of a stop mutation had isolated digital clubbing.

Clubbing is a feature of pachydermoperiostosis (PDP), a rare genodermatosis characterized by pachydermia, digital clubbing, periostosis, and an excess of affected males.
Although usually an autosomal dominant model with incomplete penetrance and variable expression, both autosomal recessive and $\mathrm{X}$-linked inheritance have been suggested in some PDP families.

\section{Secondary Clubbing}

Secondary clubbing occurs due to multiple systemic causes described in the following text.

\section{Method of Examination}

Anatomic considerations, such as the classic measurement of the Lovibond angle or the more recently derived index of nail curvature by Goyal et al, usually can be identified on simple physical examination and can be used to identify digital clubbing and to monitor this dynamic process objectively. ${ }^{1}$ Various imaging modalities have been used not only to evaluate clubbing but also to help identify possible clues to its development. Details of physical examination are given below.

\section{Pathophysiology}

The specific pathophysiologic mechanism of digital clubbing remains unknown. Many theories have been proposed, yet none have received widespread acceptance as a comprehensive explanation for the phenomenon of digital clubbing. As stated best by Samuel West in 1897, "Clubbing is one of those phenomena with which we are all so familiar that we appear to know more about it than we really do."

Alterations in size and configuration of the clubbed digit result from changes in the nail bed, beginning with increased interstitial edema early in the process. As clubbing progresses, the volume of the terminal portion of the digit may increase because of an increase in the vascular connective tissue and change in quality of the vascular connective tissue, although some cases have been associated with spurs of bone on the terminal phalanx. Different pathologic processes may follow different pathways to a common end. 
Many studies have shown increased blood flow in the clubbed portion of the finger. High-resolution magnetic resonance imaging (MRI) using a contrast agent showed nail bed hypervascularization as linked with clubbed nails. Most researchers agree that this results from an increase in distal digital vasodilation, the cause of which is unknown. Also unknown is the exact mechanism by which increased blood flow results in changes in the vascular connective tissue under the nail bed. Whether the vasodilation results from a circulating or local vasodilator, neural mechanism, response to hypoxemia, genetic predisposition, or a combination of these or other mediators is not agreed on currently.

Evidence that favors the presence of a circulating vasodilator derives from the association of clubbing with cyanotic congenital heart disease. Many potential vasodilators, which usually are inactivated as blood passes through the lungs, bypass the inactivation process in patients with right-to-left shunts. Patients with tetralogy of Fallot (TOF) with substantial right-to-left shunting have a high incidence of clubbing. After surgical correction eliminates the right-to-left shunt, the clubbing improves. Also previously observed is clubbing confined to the feet in patients with late untreated patent ductus arteriosus (PDA) in whom blood from the pulmonary artery bypasses the lungs and is shunted into the descending aorta. In the absence of a shunt, the circulating vasodilator may be produced by the lung tissue, or, possibly, it passes through the pulmonary circulation without getting inactivated. Proposed vasodilatory factors include ferritin, prostaglandins, bradykinin, adenine nucleotides, and 5-hydroxytryptamine.

A neural mechanism has been proposed with particular consideration of the vagal system. An increased incidence of digital clubbing has been associated with the pathology and disease of vagally innervated organs. Furthermore, regression of clubbing after vagotomy has been reported. Although some factor related to the vagal system is a possible contributor to the development of clubbing, especially clubbing occurring with hypertrophic osteoarthropathy (HOA), the hypothesis of a neural mechanism has decreased in popularity because of the lack of evidence of clubbing in neurologic disorders and the presence of clubbing in diseases of organs not innervated by the vagal system.

Hypoxia has been proposed as an alternative explanation for clubbing in cyanotic heart disease and pulmonary diseases. An increase in hypoxia may activate local vasodilators, consequently increasing blood flow to the distal portion of the digits; however, in most cases, hypoxia is absent in the presence of clubbing, and many diseases with noted hypoxia are not associated with clubbing.

Genetic inheritance and predisposition also may play a role in digital clubbing. Hereditary clubbing is observed in two forms, including idiopathic hereditary clubbing and clubbing associated with PDP. The two forms are believed to be separate entities. Both demonstrate autosomal dominant inheritance with incomplete penetrance.

More recently, platelet-derived growth factor released from fragments of platelet clumps or megakaryocytes has been proposed as the mechanism by which digital clubbing occurs. The fragments are large enough to lodge in the vascular beds of the fingertips, and, subsequently, they release platelet-derived growth factor. This factor has been shown to have general growth-promoting activity and causes increased capillary permeability and connective tissue hypertrophy. ${ }^{2}$

\section{Epidemiology}

\section{Frequency}

Idiopathic or primary clubbing is rare, while the occurrence of secondary clubbing depends on the underlying disease.

Primary digital clubbing has been reported to occur in $89 \%$ of patients diagnosed with PDP. ${ }^{3}$ This syndrome most often occurs in young males.

Of patients with idiopathic pulmonary fibrosis, $65 \%$ have clinical digital clubbing. In these patients, an increased occurrence has been shown in patients with higher grades of smooth muscle proliferation in the lungs.

Clubbing has been reported in $29 \%$ of patients with lung cancer and is observed more commonly in patients with non-small-cell lung carcinoma (35\%) than in patients with small cell lung carcinoma (4\%).

Digital clubbing was reported in $38 \%$ of patients with Crohn's disease, $15 \%$ of patients with ulcerative colitis, and $8 \%$ of patients with proctitis. Clubbing was observed in up to one-third of Ugandan patients with pulmonary tuberculosis. It was not associated with stage of human immunodeficiency virus (HIV) infection, extensive disease, or hypoalbuminemia.

\section{History}

The development of clubbing usually is gradual enough that many patients are unaware of its presence; however, some patients may report swelling of the distal portion of the digits, which may be bilateral or unilateral or may involve a single digit. Although clubbing typically is painless, it rarely may present with pain in the fingertips. Rapid postoperative resolution of clubbing in a few days was described in a patient with aortic and mitral valve replacement due to infective endocarditis. HOA may occur as an isolated calcaneal periostitis bilaterally.

\section{Physical Examination}

Clubbing is a clinical finding characterized by bulbous fusiform enlargement of the distal portion of a digit (-Fig. 1).

When the profile of the distal digit is viewed, the angle made by the proximal nail fold and nail plate (Lovibond angle) typically is less than or equal to 160 degrees. ${ }^{4}$ In clubbing, the angle flattens out and increases as the severity of the clubbing increases. If the angle is greater than 180 degrees, definitive clubbing exists. An angle between 160 and 180 degrees falls in a gray area and may indicate early stages of clubbing or a pseudoclubbing phenomenon.

Individuals without clubbing display a diamond-shaped window at the base of the nail beds when the dorsums of two fingers from the opposite hands are opposed. The distal angle between the two opposed nails should be minimal. In individuals with digital clubbing, the diamond window is obliterated and the distal angle between the nails increases with increasing severity of clubbing. 


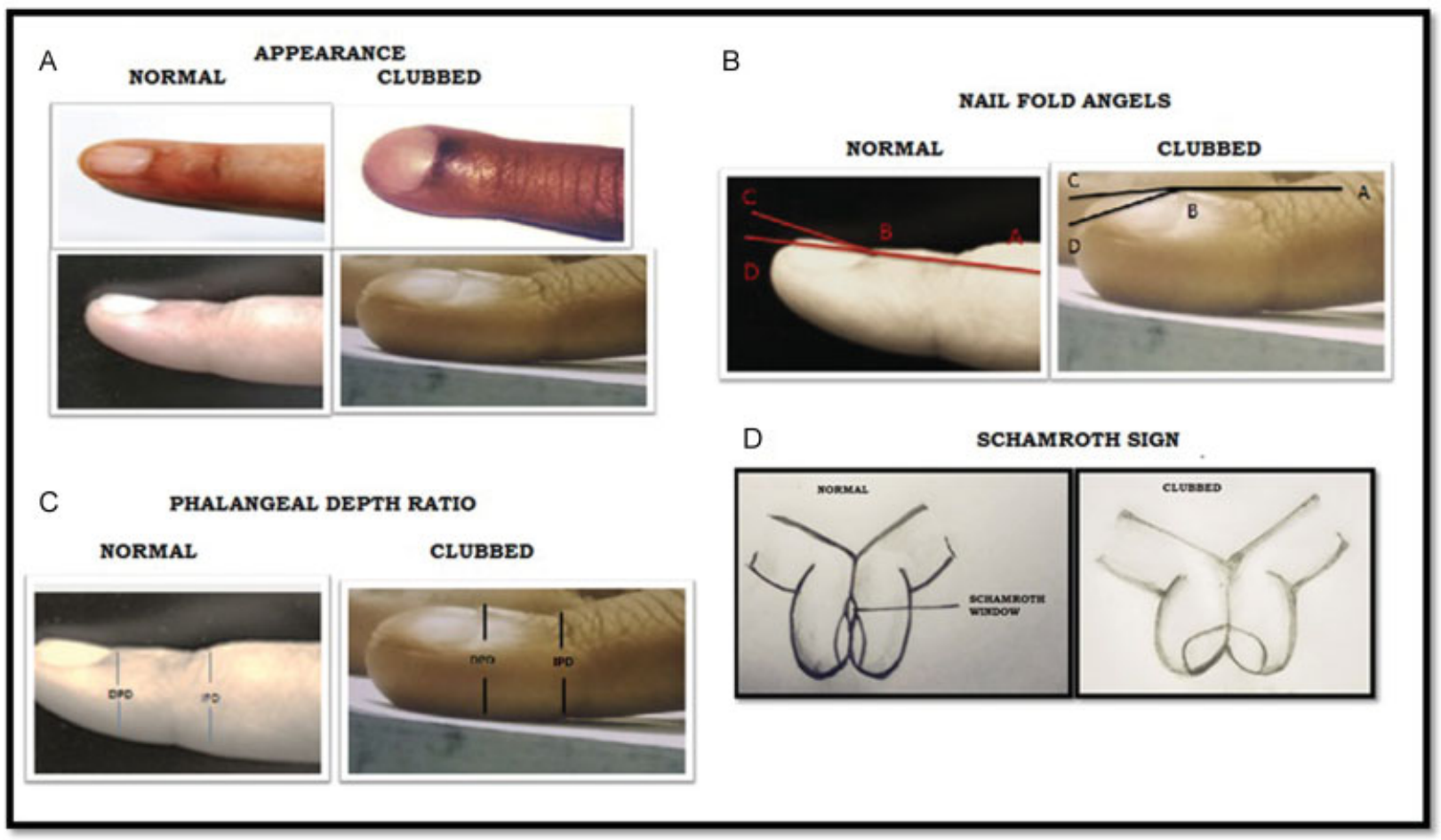

Fig. 1 Comparison of normal and clubbed fingernails: (A) Normal finger viewed from above and in profile, and the changes occurring in established clubbing, viewed from above and in profile. (B) The finger on the left demonstrates normal profile (ABC) and normal hyponychial $(A B D)$ nail fold angles. The clubbed finger on the right shows increased profile and hyponychial nail fold angles. (C) Distal phalangeal finger depth (DPD)-interphalangeal finger depth (IPD) represents the phalangeal depth ratio. In normal fingers, the IPD is greater than the DPD. In clubbing, this relationship is reversed. (D) Demonstrating the Schamroth sign.

The nail moves more freely in patients with clubbing; therefore, the examiner may note a spongy sensation as the nail is pressed toward the nail plate. The sponginess results from increased fibrovascular tissue between the nail and the phalanx. The skin at the base of the nail may be smooth and shiny.

Obliteration in clubbed fingers of the diamond-shaped window normally produced when the dorsal surfaces of the corresponding finger of each hand are opposed (Schamroth sign) may useful for the identification of clubbing.

\section{Grading of Clubbing}

Grade 1: Nail bed fluctuation.

Grade 2: Obliteration of the Lovibond angle.

Grade 3: Parrot beaking.

Grade 4: Hypertrophic osteo-arthropathy (HOA).

\section{Causes}

Clubbing can be idiopathic or secondary to many underlying pathologies in various organ systems. ${ }^{5}$

Causes of idiopathic or primary clubbing include PDP, familial clubbing, and HOA.

Causes of secondary clubbing include the following: ${ }^{6}$

Pulmonary disease: Lung cancer, cystic fibrosis, interstitial lung disease, idiopathic pulmonary fibrosis, sarcoidosis, lipoid pneumonia, empyema, pleural mesothelioma, pul- monary artery sarcoma, cryptogenic fibrosing alveolitis, lung hydatid cysts, surfactant protein C p, V39L mutation, ${ }^{7}$ and pulmonary metastases. In emphysema, secondary polycythemia is generally present due to severe pulmonary insufficiency producing cyanosis and clubbing of the fingers may occur. ${ }^{8}$

Cardiac causes are detailed in the following text. ${ }^{9}$

Gastrointestinal disease: Ulcerative colitis, Crohn's disease, primary biliary cirrhosis, cirrhosis of the liver, hepatopulmonary syndrome, leiomyoma of the esophagus, achalasia, Whipple' disease, and peptic ulceration of the esophagus. ${ }^{10}$

Skin disease: PDP, Bureau-Barrière-Thomas syndrome, Fischer's syndrome, palmoplantar keratoderma, and Volavsek's syndrome. ${ }^{11}$

Malignancies: Thyroid cancer, thymus cancer, Hodgkin's disease, ${ }^{12}$ and disseminated chronic myeloid leukemia (POEMS [polyneuropathy, organomegaly, endocrinopathy, monoclonal gammopathy, and skin changes] syndrome. In lung malignancy, skeletal-connective tissue syndromes include clubbing in 30\% of cases (usually non-small-cell carcinomas) and hypertrophic pulmonary osteoarthropathy in 1 to $10 \%$ of cases (usually adenocarcinomas), with periostitis and clubbing causing pain, tenderness, and swelling over the affected bones and a positive bone scan. ${ }^{13}$

Miscellaneous conditions: Acromegaly, thyroid acropachy, pregnancy, an unusual complication of severe secondary 
hyperparathyroidism, sickle cell disease, and hypoxemia possibly related to long-term smoking of cannabis. ${ }^{14}$ Thyroid acropachy refers to a form of clubbing found in less than $1 \%$ of patients with Graves' disease. It is so strongly associated with thyroid dermopathy that an alternative cause of clubbing should be sought in a Graves' patient without coincident skin and orbital involvement. ${ }^{15}$

HOA in adults is often a sign of internal cancer. Other stigmata may also be evident, such as acquired keratoderma taking on a yellow velvety appearance with accentuation of dermatoglyphic lines.

As a paraneoplastic syndrome, it is most commonly associated with non-small-cell lung cancer, although it may occur with metastatic melanoma and other cancers. Hypertrophic pulmonary osteoarthropathy is evident in 1 to $5 \%$ of all patients with non-small-cell lung cancer.

Among hemodialysis patients with end-stage renal disease, the finding of clubbing was linked with the calciumphosphorus product.

\section{Diagnostic Considerations}

HOA is a syndrome defined by chronic proliferative periostitis of the long bones, digital clubbing, and joint swelling. HOA is characterized by clubbing of digits and, in more advanced stages, by periosteal new bone formation and synovial effusions. ${ }^{16}$ HOA occurs in primary or familial form and usually begins in childhood. The secondary form of HOA is associated with intrathoracic malignancies, suppurative lung disease, congenital heart disease, and a variety of other disorders, and is more common in adults. Clubbing is almost always a feature of HOA but can occur as an isolated manifestation. The presence of clubbing in isolation is generally considered to represent either an early stage or an element in the spectrum of HOA. The presence of only clubbing in a patient usually has the same clinical significance as HOA. ${ }^{17}$

Primary or familial HOA, also referred to as PDP or Touraine-Solente-Golé syndrome, usually begins insidiously at puberty. In a smaller number of patients, the onset is in the first year of life. The disorder is inherited as an autosomal dominant trait with variable expression and is nine times more common in boys than in girls. Approximately one-third of patients have a family history of primary HOA.

Primary HOA is characterized by clubbing, periostitis, and unusual skin features. A small number of patients with this syndrome do not express clubbing. The skin changes and periostitis are prominent features of this syndrome. The skin becomes thickened and coarse. Deep nasolabial folds develop, and the forehead may become furrowed. Patients may have heavy-appearing eyelids and ptosis. The skin is often greasy, and there may be excessive sweating of the hands and feet. Patients may also experience acne vulgaris, seborrhea, and folliculitis. In a few patients, the skin over the scalp becomes very thick and corrugated, a feature that has been descriptively termed cutis verticis gyrata. The distal extremities, particularly the legs, become thickened owing to proliferation of new bone and soft tissue; when the process is extensive, the distal lower extremities resemble those of an elephant. The periostitis is usually not painful, as it may be in secondary HOA. Clubbing of the fingers may be extensive, producing large, bulbous deformities, and clumsiness. Clubbing also affects the toes. Patients may experience articular and periarticular pain, especially in the ankles and knees, and joint motion may be mildly restricted owing to periarticular bone overgrowth. Noninflammatory effusions occur in the wrists, knees, and ankles. Synovial hypertrophy is not found. Associated abnormalities observed in patients with primary HOA include hypertrophic gastropathy, bone marrow failure, female escutcheon, gynecomastia, and cranial suture defects. In patients with primary HOA, the symptoms disappear when adulthood is reached. ${ }^{18}$

HOA secondary to an underlying disease occurs more frequently than primary HOA. It accompanies a variety of disorders and may precede clinical features of the associated disorder by months. Clubbing is more frequent than the full syndrome of HOA in patients with associated illnesses. Because clubbing evolves over months and is usually asymptomatic, it is often recognized first by the physician and not the patient. Patients may experience a burning sensation in their fingertips. Clubbing is characterized by widening of the fingertips, enlargement of the distal volar pad, convexity of the nail contour, and the loss of the normal 15-degree angle between the proximal nail and cuticle. The thickness of the digit at the base of the nail is greater than that at the distal interphalangeal joint. An objective measurement of finger clubbing can be made by determining the diameter at the base of the nail and at the distal interphalangeal joint of all 10 digits. Clubbing is present when the sum of the individual digit ratios is greater than 10 . At the bedside, clubbing can be appreciated by having the patient place the dorsal surface of the distal phalanges of the fourth fingers together with the nails of the fourth fingers opposing each other. Normally, an open area is visible between the bases of the opposing fingernails. When clubbing is present, this open space is no longer visible. The base of the nail feels spongy when compressed, and the nail can be easily rocked on its bed. Marked periungual erythema is usually present. When clubbing is advanced, the finger may have a drumstick appearance, and the distal interphalangeal joint can be hyperextended. Periosteal involvement in the distal extremities may produce a burning or deep-seated aching pain. The pain can be quite incapacitating and is aggravated by dependency and relieved by elevation of the affected limbs. The overlying soft tissue may be swollen and the skin slightly erythematous. Pressure applied over the distal forearms and legs may be quite painful.

Patients may also experience joint pain, most often in the ankles, wrists, and knees. Joint effusions may be present; usually they are small and noninflammatory. The small joints of the hands are rarely affected. Severe joint or bone pain may be the presenting symptom of an underlying lung malignancy and may precede the appearance of clubbing. In addition, the progression of HOA tends to be more rapid when associated with malignancies, most notably 
Table 1 Disorders associated with hypertrophic osteoarthropathy

\begin{tabular}{|l|}
\hline Pulmonary \\
\hline Bronchogenic carcinoma and other neoplasms \\
\hline Lung abscesses, empyema, bronchiectasis \\
\hline Chronic interstitial pneumonitis \\
\hline Cystic fibrosis \\
\hline Chronic obstructive lung disease \\
\hline Sarcoidosis \\
\hline Gastrointestinal \\
\hline Inflammatory bowel disease \\
\hline Sprue \\
\hline Neoplasms: esophagus, liver, bowel \\
\hline Cardiovascular \\
\hline Cyanotic congenital heart disease \\
\hline Subacute bacterial endocarditis \\
\hline Infected arterial grafts $^{\text {a }}$ \\
\hline Aortic aneurysm ${ }^{\text {b }}$ \\
\hline Aneurysm of major extremity artery \\
\hline Patent ductus arteriosus \\
\hline Arteriovenous fistula of major extremity vessel \\
\hline Thyroid \\
\hline Thyroid Acropachy \\
\hline Hyperthyroidism (Graves' disease) \\
\hline
\end{tabular}

${ }^{a}$ Unilateral involvement.

bilateral lower extremity involvement.

bronchogenic carcinoma. Unlike primary HOA, excessive sweating and oiliness of the skin and thickening of the facial skin are uncommon in secondary HOA.

HOA occurs in 5 to $10 \%$ of patients with intrathoracic malignancies, the most common being bronchogenic carcinoma and pleural tumors (-Table 1). Lung metastases infrequently cause HOA. HOA is also seen in patients with intrathoracic infections, including lung abscesses, empyema, bronchiectasis, chronic obstructive lung disease, and, uncommonly, pulmonary tuberculosis. HOA may also accompany chronic interstitial pneumonitis, sarcoidosis, and cystic fibrosis. In the latter, clubbing is more common than the full syndrome of HOA. Other causes of clubbing include congenital heart disease with right-to-left shunts; bacterial endocarditis; Crohn's disease; ulcerative colitis, sprue; and neoplasms of the esophagus, liver, and small and large bowel. In patients with congenital heart disease with right-to-left shunts, clubbing alone occurs more often than the full syndrome of HOA.

Unilateral clubbing has been found in association with aneurysms of major extremity arteries, with infected arterial grafts, and with arteriovenous fistulas of the brachial vessels. Clubbing of the toes but not fingers has been associated with an infected abdominal aortic aneurysm and PDA. Clubbing of a single digit may follow trauma and has been reported in tophaceous gout and sarcoidosis. While clubbing occurs more commonly than the full syn- drome in most diseases, periostitis in the absence of clubbing has been observed in the affected limb of patients with infected arterial grafts.

Hyperthyroidism (Graves' disease), treated or untreated, is occasionally associated with clubbing and periostitis of the bones of the hands and feet. This condition is referred to as thyroid acropachy. Periostitis is asymptomatic and occurs in the midshaft and diaphyseal portion of the metacarpal and phalangeal bones. The long bones of the extremities are seldom affected. Elevated levels of long-acting thyroid stimulator are found in the serum of these patients.

In some instances it is occupational, for example in jackhammer operators.

Pseudoclubbing is defined as an over curvature of the nails in both the longitudinal and transverse axes, with preservation of a normal Lovibond angle.

\section{Cardiac Causes of Clubbing}

In cyanotic congenital heart diseases, clubbing occurs as sequelae of hypoxemia. Clubbing of the fingers and toes occurs after 3 months of age and is proportional to the level of cyanosis. Clubbing implies the presence of central shunting, although it has also been described with endocarditis. ${ }^{19}$

\section{Eisenmenger's Pulmonary Arterial Hypertension}

Patients with Eisenmenger's syndrome also have central cyanosis and clubbing of the digits. ${ }^{20}$ Although clubbing is common with Eisenmenger's syndrome, it typically is not a feature of idiopathic pulmonary arterial hypertension (IPAH). Clubbing is invariable once cyanosis becomes persistent and may progress to HOA with arthralgia and joint effusions.

Pulmonary veno-occlusive disease and pulmonary capillary hemangiomatosis anomalies of pulmonary veins: Cyanosis, syncope, hemoptysis, and finger clubbing have been inconsistent findings. Cyanosis and clubbing are unusual features of primary pulmonary arteriolar hypertension, and their presence may alert one to the diagnosis of pulmonary veno-occlusive disease.

Patients with Eisenmenger's PDA can have pink nail beds on the right ( $>$ left) hand and cyanosis and clubbing of both the feet, so-called "differential cyanosis." Retarded growth and development are reserved for infants with a large ventricular septal defect (VSD) and congestive heart failure. Cyanosis and clubbing appear when pulmonary stenosis or pulmonary vascular disease reverses the shunt. Patients with large nonrestrictive Eisenmenger's VSDs present with central cyanosis and clubbing of the nail beds. ${ }^{21,22}$ In atrial septal defect (ASD), cyanosis and clubbing accompany the development of a right-to-left shunt. If three is no differential clubbing in Eisenmenger's PDA, there are two possibilities: an another proximal shunt like VSD or right subclavian aberrantly taking origin distal to the PDA from the descending thoracic aorta.

\section{Tetralogy of Fallot}

Degree of clubbing present corresponds to severity of arterial desaturation. In TOF, clubbing develops if cyanosis is long 
standing. ${ }^{23}$ After palliative surgery, clubbing and cyanosis persist. $^{24}$

\section{Double-outlet Right Ventricle}

Clubbing is present in group 1 (subaortic VSD and pulmonary stenosis), group 2 (subpulmonary VSD with or without pulmonary stenosis), and group 4 (subaortic VSD with pulmonary vascular obstructive disease), but not obviously in group 3 (subaortic VSD without pulmonary stenosis). ${ }^{25}$

\section{Abnormal Systemic Venous Connections \\ Most patients with an isolated persistent left superior vena cava (LSVC) to a partially or completely unroofed coronary sinus also have a large coronary sinus ostium that functions as an interatrial communication (Raghib's syndrome). The hemodynamic consequences of the Raghib's syndrome are cyanosis and left-to-right shunting. ${ }^{26}$ Systemic arterial desaturation is caused by mixing of LSVC blood with pulmonary venous blood in the left atrium. The degree of arterial desaturation is related to the net right-to-left shunt, in the LA. In most patients, the arterial oxygen saturation ranges between 85 and 95\%. These patients exhibit varying degrees of cyanosis, clubbing of the nail beds, and polycythemia. 27 \\ Left atrial drainage of the right SVC is a rare malformation that typically manifests itself as unexplained cyanosis and clubbing in patients who do not have any other signs of a heart defect.}

\section{Vascular Anomalies \\ The arteriovenous malformation (AVM) or arteriovenous fistula (AVF) creates a right-to-left shunt from the pulmonary arteries to the pulmonary veins, resulting in systemic arterial desaturation and secondary polycythemia. The clinical find- ings correlate with the amount of right-to-left shunting. The classic triad of cyanosis, clubbing, and polycythemia usually appears during early adult life. ${ }^{28}$}

\section{Total Anomalous Pulmonary Venous Connection}

Clubbing is occasionally seen in the patient who survives infancy. $^{29}$

\section{Tricuspid Atresia}

Clubbing of the fingers is common in children who survive beyond the first 2 years but may occasionally develop as early as 3 or 4 months. In older patients who either have not undergone any surgery or who have undergone only a palliative aortopulmonary shunt, cyanosis will be more apparent and clubbing of the digits will develop. ${ }^{30}$

\section{D - Transposition of the Great Arteries}

Clubbing of fingers and toes is absent, and it generally does not appear unless the infant survives to about age 6 months.

\section{Epstein's Anomaly}

In Ebstein's anomaly in older infants and children, cyanosis and clubbing are mild.

\section{Truncus Arteriosus}

In truncus arteriosus, in older patients who either have not undergone any surgery or who have undergone only a palliative aortopulmonary shunt, cyanosis will be more apparent and clubbing of the digits will develop. ${ }^{31}$

\section{After Palliative Surgery}

Progressive cyanosis with its complications can result from worsening right ventricular outflow tract obstruction, gradual stenosis and occlusion of palliative aortopulmonary shunts, or the development of pulmonary hypertension (sometimes seen after Waterston's or Potts' shunts). Progressive ascending aortic dilation and aortic regurgitation can occur. Central cyanosis and clubbing are invariably present. ${ }^{32}$

\section{Infective Endocarditis}

In infective endocarditis, clubbing is present in 10 to $20 \%$ of patients.

\section{Cardiac Tumors}

Large left atrial myxomas are particularly apt to produce constitutional symptoms. These symptoms include fever, weight loss, clubbing of the fingers and toes, Raynaud's phenomenon, and myalgia and arthralgia. Other unusual manifestations of cardiac myxomas include polycythemia with or without associated arterial hypoxia, and clubbing (in both left and right atrial myxomas) associated with a rightto-left shunt at the atrial level through a patent foramen ovale or ASD. ${ }^{33}$

\section{Right Atrial Tumors}

Patients frequently present with rapidly progressive rightsided heart failure and also new-onset heart murmurs because of mechanical interference with the tricuspid valve by the tumor. In patients with a patent foramen ovale, the buildup of right atrial pressure can produce right-to-left intracardiac shunting and result in systemic hypoxia, cyanosis, clubbing, and polycythemia.

\section{Hemorrhagic Telangiectasia}

In the lungs, resulting in hypoxemia, hemoptysis, polycythemia, clubbing, paradoxical embolization through the right-to-left shunt, and a hyperdynamic circulation. ${ }^{34}$ Children with hereditary hemorrhagic telangiectasia (HHT) and pulmonary AVMs are often asymptomatic. Routine screening for the presence of AVMs, when they have clinical signs like clubbing, should be performed regardless of symptomatology. ${ }^{35}$

\section{Cyanosis and Clubbing}

Usually central cyanosis and clubbing go hand in hand. If long-standing cyanosis is present without clubbing, suspect circulating methemoglobin and by even smaller quantities of sulfhemoglobin. In both these conditions, the arterial partial pressure of oxygen $\left(\mathrm{PaO}_{2}\right)$ remains normal. Peripheral cyanosis or acutely developing central cyanosis is not associated with clubbed digits. 


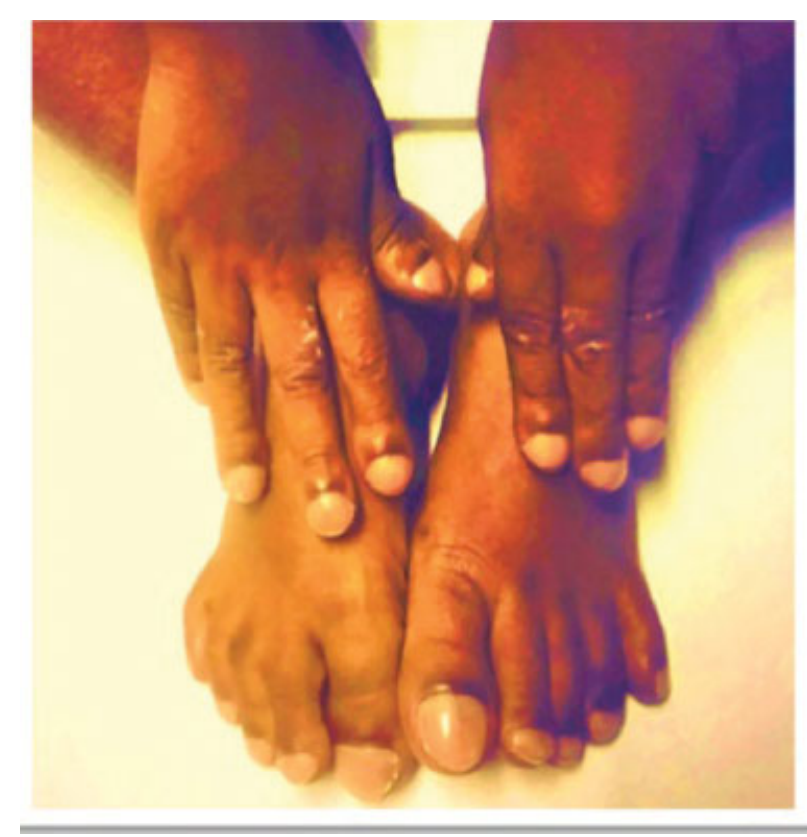

Fig. 2 Symmetric Cyanosis.

\section{Symmetric Cyanosis and Clubbing}

Equal cyanosis and clubbing of hands and feet caused by transposition of the great vessels and a VSD without PDA (-Fig. 2).

\section{Asymmetric Cyanosis and Clubbing}

Differential cyanosis provides information about anatomy. ${ }^{36}$ Cyanosis and clubbing of the toes associated with pink fingernails of the right hand and cyanosis and clubbing of the left hand are caused by a PDA with normally related great vessels and a reversed shunt as a result of pulmonary hypertension, with the PDA delivering cyanotic blood to the left arm and lower extremities. The same color pattern results from interruption of the aortic arch and a PDA delivering desaturated blood to the legs. However, if the right subclavian artery arises proximal to the aortic obstruction, the right hand can be pink and the left hand cyanotic. When an anomalous right subclavian artery originates from the descending aorta, both hands are cyanotic. Cyanosis of the fingers greater than in the toes indicates complete transposition of the great vessels with preductal Coarctation or complete interruption of the aortic arch, pulmonary hypertension, and a reverse shunt through a PDA, (with shunting of the more oxygenated pulmonary artery blood as seen transposition physiology) delivers blood with higher saturation to the lower extremities.

In Eisenmenger's VSD with PDA, when shunt reversal is there as both levels, the patient can have both upper and lower limb cyanosis and clubbing, instead of differential clubbing due to PDA. Still there may be differential saturations in upper and lower limbs along with low basal oxygen saturation. For example in - Fig. 3, this patient has Eisenmenger's VSD with PDA with shunt reversal at both levels. The patient developed diffuse clubbing with more desatu-

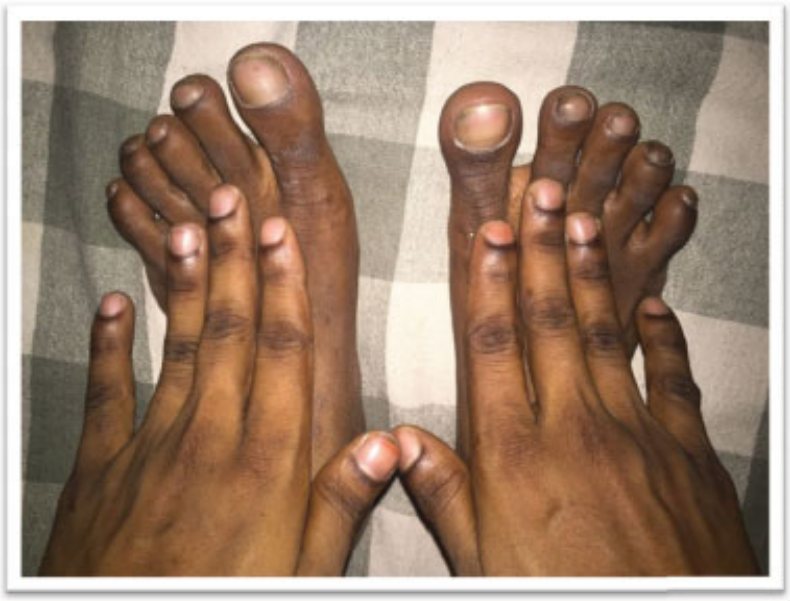

Fig. 3 Clubbing of both upper and lower limbs with more clubbing of lower limbs. This patient has Eisenmenger's VSD with PDA with shunt reversal at both levels. PDA, patent ductus arteriosus; VSD, ventricular septal defect.

rated blood to lower limb $\left(\mathrm{SO}_{2}=62 \%\right)$ than upper limb $\left(\mathrm{SO}_{2}=78 \%\right)$ (Personal communication).

\section{Diagnosis of Heart Diseases in Pregnant Women}

On examination, cyanosis or clubbing, a loud systolic murmur (grade 3 or louder), or any diastolic murmur suggests heart disease.

\section{Imaging Studies}

\section{Roentgenogram}

Radiographic changes in patients with digital clubbing vary and include bone dissolution, bone formation, or no change in the bone of the distal phalanx. The types of changes may depend on the underlying pathologic processes, as well as the duration of the processes. The severity of soft tissue changes in clubbed digits has not been found to correlate with the type of bone change or the degree of radiographic change. Probably, the lysis of bone predominates in the digits of patients with congenital cyanotic heart disease, while hypertrophy predominates in the digits of patients with clubbing secondary to pulmonary conditions. As an alternate view, hypertrophy may occur earlier in the process of clubbing, and, eventually, it may change to osteolysis as the process becomes chronic.

\section{Nuclear Imaging}

Technetium Tc99m skeletal imaging with good-quality views may be helpful in determining the presence and extent of bone changes in clubbed digits, which show increased uptake of the radionuclide. The increased, intense, symmetric uptake typically is localized to the nail beds and may result from increased blood flow and changes in the surrounding soft tissues.

\section{Thermography}

Thermography is another imaging modality being studied for use in diagnosis and monitoring of patients with 
digital clubbing. Patients may show increased temperature in the distal digits, which can be attributed to an increase in blood flow secondary to vasodilation. Not all patients with clubbing have positive thermographic results. ${ }^{37}$

\section{Positron Emission Tomography (PET)}

PET also has been used to study the glucose metabolism of clubbed digits. An increased signal, indicating increased glucose metabolism, has been demonstrated in the distal part of the clubbed fingers. These changes are not seen in fingertips with normal morphology. The increase in signal supports the theory that clubbing is caused by the presence of a factor (e.g., platelet-derived growth factor) that increases cellular metabolism. ${ }^{38}$

\section{Computed Tomography (CT) and Magnetic Resonance Imaging (MRI)}

Other imaging studies, such as CT or MRI, may be helpful in evaluating the patient for the primary pathologic process causing the clubbing. ${ }^{39}$ Use of high-frequency ultrasound imaging has also been advocated for the diagnosis of clubbing. Ultrasound in PHO may show echogenic tissue surrounding the long bones, likely a reflection of edema and inflammatory tissue. ${ }^{40,41}$

\section{Histologic Findings}

Microscopically, the collagen fibrils and cells are separated by a distance greater than that seen in histologically normal specimens. This increased separation results in a less dense nail bed matrix. Primitive fibroblasts are seen with large nuclei, basophilic cytoplasm, and long reticular processes. Increased and scattered extravascular lymphocytes and, less often, a moderately increased number of tissue eosinophils also are noted in the nail beds of some specimens. The periosteum of the nail bed may be thickened with increased vascular penetration.

Eventually, increased collagen is laid down in all types of chronic clubbing. The mat of collagen fibers may be abnormally thick and dense. The walls of the vascular components increase in thickness and are encased in a thick fibrous sheet. At this stage of clubbing, the histologic and morphologic changes probably are irreversible.

\section{Prognosis}

Since clubbing of the fingers is a clinical finding, it is not an independent cause of mortality; however, mortality associated with underlying pathology in patients with secondary clubbing widely varies.

Morbidity is minimal and is typically associated with the cosmetic appearance of clubbed digits.

Treatment of the underlying pathologic condition may decrease the clubbing or, potentially, reverse it if performed early enough. Once substantial chronic tissue changes, including increased collagen deposition, have occurred, reversal is unlikely. Prognosis of the underlying disease should be determined on an individual basis.

\section{References}

1 Goyal S, Griffiths AD, Omarouayache S, Mohammedi R. An improved method of studying fingernail morphometry: application to the early detection of fingernail clubbing. J Am Acad Dermatol 1998;39(4 Pt 1):640-642

2 Dickinson CJ, Martin JF. Megakaryocytes and platelet clumps as the cause of finger clubbing. Lancet 1987;2(8573):1434-1435

3 Castori M, Sinibaldi L, Mingarelli R, Lachman RS, Rimoin DL, Dallapiccola B. Pachydermoperiostosis: an update. Clin Genet 2005;68(06):477-486

4 Mann Z, Libby B. The history and physical examination: an evidence-based approach. In: Braunwald's Heart Disease: A Textbook of Cardiovascular Medicine. 10th ed. St. Louis, MS: Mosby: Elsevier; 2015:98, chap 11

5 Fawcett RS, Linford S, Stulberg DL. Nail abnormalities: clues to systemic disease. Am Fam Physician 2004;69(06):1417-1424

6 Kasper D, Fauci A, Hauser S, Longo D, Jameson JL, Loscalzo J. Alteration in circulatory and respiratory function. In: Harrison's Principles of Internal Medicine. 19th ed. New York, NY: McGrawHill Education; 2015:47e3, chap 47e

7 Chen JH, Zhao DY, An SH, Zheng YJ, Wang HP, Ma HL. [Clinical manifestations of three cases of surfactant protein $\mathrm{C} \mathrm{p}$. V39L mutation] [in Chinese]. Zhonghua $\mathrm{Er}$ Ke Za Zhi 2017; 55(06):457-461

8 Kasper D, Fauci A, Hauser S, Longo D, Jameson JL, Loscalzo J. Cough and hemoptysis. In: Harrison's Principles of Internal Medicine. 19th ed. New York, NY: McGraw-Hill Education; 2015:244-246, chap 48

9 Kasper D, Fauci A, Hauser S, Longo D, Jameson JL, Loscalzo J. Hypoxia and cyanosis. In: Harrison's Principles of Internal Medicine.19th ed. New York, NY: McGraw-Hill Education; 2015:249-250, chap 49

10 Kasper D, Fauci A, Hauser S, Longo D, Jameson JL, Loscalzo J. Diarrhorea and constipation. In: Harrison's Principles of Internal Medicine. 19th ed. New York, NY: McGraw-Hill Education; 2015: 270, chap 55

11 Kasper D, Fauci A, Hauser S, Longo D, Jameson JL, Loscalzo J. Skin manifestations of internal disease. In: Harrison's Principles of Internal Medicine. 19th ed. New York, NY: McGraw-Hill Education; 2015:361, chap 72

12 Mullins GM, Lenhard RE Jr. Digital clubbing in Hodgkin's disease. Johns Hopkins Med J 1971;128(03):153-157

13 Kasper D, Fauci A, Hauser S, Longo D, Jameson JL, Loscalzo J. Plasma cell disorders. In: Harrison's Principles of Internal Medicine. 19th ed. New York, NY: McGraw-Hill Education; 2015:718, chap 178

14 Schuller A, Cottin V, Hot A, Cordier JF. Finger clubbing and altered carbon monoxide transfer capacity in cannabis smokers. Eur Respir J 2008;31(02):473-474

15 Kasper D, Fauci A, Hauser S, Longo D, Jameson JL, Loscalzo J. Disorders of thyroid. In: Harrison's Principles of Internal Medicine. 19th ed. New York, NY: McGraw-Hill Education; 2015:2295, chap 405

16 Pineda CJ, Guerra JJr, Weisman MH, Resnick D, Martinez-Lavin M. The skeletal manifestations of clubbing: a study in patients with cyanotic congenital heart disease and hypertrophic osteoarthropathy. Semin Arthritis Rheum 1985;14(04):263-273

17 Joseph PAM. Ventricular septal defect. In: Perloff's Clinical Recognition of Congenital Heart Disease. 6th ed. Philadelphia, PA: Elsevier Saunders; 2012:292, chap 17

18 Kasper D, Fauci A, Hauser S, Longo D, Jameson JL, Loscalzo J. Arthritis associated with systemic disorders and other arthritis. 
In: Harrison's Principles of Internal Medicine. 19th ed. New York, NY: McGraw-Hill Education; 2015:2245-2246, chap 397

19 Mann Z, Libby B. Principal of cardiovascular genetics. In: Braunwald's Heart Disease: A Textbook of Cardiovascular Medicine. 10th ed. Philadelphia, PA: Elsevier Saunders; 2015:67, chap 8

20 Mann Z, Libby B. Congenital heart disease. In: Braunwald's Heart Disease: A Textbook of Cardiovascular Medicine. 10th ed. Philadelphia, PA: Elsevier Saunders; 2015:1397, chap 62

21 Mann Z, Libby B. Congenital heart disease. In: Braunwald's Heart Disease: A Textbook of Cardiovascular Medicine. 10th ed. Philadelphia, PA: Elsevier Saunders; 2015:1413, chap 62

22 Joseph PAM. Congenitally corrected transposition of the great arteries. In: Perloff's Clinical Recognition of Congenital Heart Disease. 6th ed. Philadelphia, PA: Elsevier Saunders; 2012.61, chap 61

23 Baniahmad O, Jarreau T, Johnson A. Misses opportunity: TOF diagnoses in 4th decade of life. J La State Med Soc 2017;169(02):54

24 Allen HD, Driscoil DJ, Shaddy RE, Feltes TF. Tetrology of Fallot. In: Moss \& Adams' Heart Disease in Infants, Children, and Adolescents, Including the Fetus and Young Adult. 9th ed. Philadelphia, PA: Wolters Kluwer; 2012:895, chap 43

25 Joseph PAM. Double outlet ventricle. In: Perloff's Clinical Recognition of Congenital Heart Disease. 6th ed. Philadelphia, PA: Elsevier; 2012:351, chap 19

26 Allen HD, Driscoil DJ, Shaddy RE, Feltes TF. Abnormal venous connections. In: Moss \& Adams' Heart Disease in Infants, Children, and Adolescents, Including the Fetus and Young Adult. 9th ed. Philadelphia, PA: Wolters Kluwer; 2016:802, chap 38

27 Joseph PAM. Congenital anomalies of vena caval connection. In: Vena Caval Connection. Philadelphia, PA: Elsevier Saunders; 2012: 509 , chap 29

28 Allen HD, Driscoil DJ, Shaddy RE, Feltes TF. Vascular anomalies. In: Moss \& Adams' Heart Disease in Infants, Children, and Adolescents, Including the Fetus and Young Adult. 9th ed. Philadelphia, PA: Wolters Kluwer; 2016:735, chap 35

29 Allen HD, Driscoil DJ, Shaddy RE, Feltes TF. Abnormal pulmonary veins. In: Moss \& Adams' Heart Disease in Infants, Children, and Adolescents, Including the Fetus and Young Adult. 9th ed. Philadelphia, PA: Wolters Kluwer; 2016:780, chap 37
30 Allen HD, Driscoil DJ, Shaddy RE, Feltes TF. Tricuspid atresia. In: Moss \& Adams' Heart Disease in Infants, Children, and Adolescents, Including the Fetus and Young Adult. 9th ed. Philadelphia, PA: Wolters Kluwer; 2016:819, chap 39

31 Allen HD, Driscoil DJ, Shaddy RE, Feltes TF. Truncus. In: Moss \& Adams' Heart Disease in Infants, Children, and Adolescents, Including the Fetus and Young Adult. 9th ed. Philadelphia, PA: Wolters Kluwer; 2016:914, chap 44

32 Mann Z, Libby B. Congenital heart disease. In: Braunwald's Heart Disease: A Textbook of Cardiovascular Medicine. 10th ed. Philadelphia, PA: Elsevier Saunders; 2015:1416, chap 62

33 Mann Z, Libby B. Tumors affecting the cardiovascular system. In: Braunwald's Heart Disease: A Textbook of Cardiovascular Medicine. 10th ed. Philadelphia, PA: Elsevier Saunders; 2015:1865, chap 85

34 Joseph PAM. Congenital pulmonary arteriovenous fistula. In: Perloff's Clinical Recognition of Congenital Heart Disease. 6th ed. Philadelphia, PA: Elsevier Saunders; 2012:517-520, chap 30

35 Gefen AM, White AJ. Asymptomatic pulmonary arteriovenous malformations in children with hereditary hemorrhagic telangiectasia. Pediatr Pulmonol 2017;52(09):1194-1197

36 Joseph PAM. Patent ductus arteriosus aortopulmonary window. In: Perloff's Clinical Recognition of Congenital Heart Disease. 6th ed. Philadelphia, PA: Elsevier Saunders; 2012: 374 , chap 20

37 Rush PJ, Giorshev C, Shore A, Levinson H. The use of thermography in clubbing. Respir Med 1992;86(03):257-259

38 Ward RW, Chin R Jr, Keyes JW Jr, Haponik EF. Digital clubbing. Demonstration with positron emission tomography. Chest 1995; 107(04):1172-1173

39 Nakamura J, Halliday NA, Fukuba E, et al. The microanatomic basis of finger clubbing-a high-resolution magnetic resonance imaging study. J Rheumatol 2014;41(03):523-527

40 Roy HS, Wang Z, Ran H, Song W, Zheng Y. Diagnosis of digital clubbing by high-frequency ultrasound imaging. Int J Dermatol 2013;52(01):1-5

41 Adams B, Amin T, Leone V, Wood M, Kraft JK. Primary hypertrophic osteoarthropathy: ultrasound and MRI findings. Pediatr Radiol 2016;46(05):727-730 